\title{
Forging a research community of practice to find out how South African children make their world mathematical
}

\begin{abstract}
In a search for ways to capture foundation phase children's competence in mathematics, a small research team was put together at a South African university four years ago. At first, working only in a single school where the objective was to model 80 learners' growth in competence over four years, the team transformed into a very different entity. This article narrates the founding and development of a community of research practice, which eventually included undergraduate- and postgraduate students, researchers from institutions in Germany, Switzerland and South Africa, teachers at local schools close to the university, and an educational research and survey company. Supported by funding from four different sources, the project is fairly close to reaching the goal of delivering a standardised mathematics competence test for 4-8 year-olds, which is a first of its kind for the country where educational measurement seems to be at a crossroads. In the story line of this community of practice, it is evident that progress can be assessed best by the learning that has been taking place in a community with a notable diversity of people and interests, but with the shared goal of investigating children's mathematical behaviour on a measure that can be trusted.
\end{abstract}

Keywords: mathematical cognition; elementary school; mathematics education; testing mathematical competence; conceptual model of mathematical competence; standardised test for mathematical competence; South African education; research collaboration; community of practice; national testing

Elizabeth Henning, University of Johannesburg, UJ Institute for Childhood Education. E-mail: ehenning@uj.ac.za
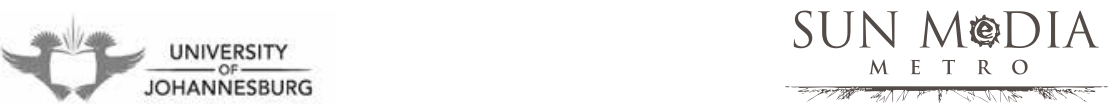


\title{
Introduction: the divide in mathematics education in South Africa
}

This narrative of how a research community in mathematics education came into being can be aptly introduced by a sentiment expressed by a blog-writer for The Scientific American (Frenkel, 2013). He writes about Pierre Deligne, who received the Abel prize for mathematics in 2013 for his work 'The Rosetta Stone of Mathematics':

\begin{abstract}
Alas, we don't hear much about this story or about the fascinating drama of ideas unfolding in modern math. Mathematics remains, in the words of poet Hans Magnus Enzensberger, "a blind spot in our culture-alien territory, in which only the elite, the initiated few have managed to entrench themselves". And this despite the fact that math is so deeply woven in the fabric of our lives and is becoming, more and more, the engine of our power, wealth, and technological progress (Frenkel, 2013).
\end{abstract}

It is such a sentiment that has been driving the small group of researchers in the Centre for Education Practice Research (CEPR) at the University of Johannesburg for the last four years. No one would disagree that the divide between the 'haves' and the 'have nots' in mathematics knowledge in South African schools is huge. The diagnostic report (South African Department of Basic Education, 2013) on the performance of children in the foundation phase on the state-mandated annual national assessments (ANA) of 2012 paints a stark picture of the divide between learners in schools that perform well and the ones that do not. There is clearly a mismatch between what the national curriculum aspires to and what is achieved in the majority of schools. It is evident from the results of the national tests that, generally, the children who already know more come to learn more.

\section{National testing and educational reform}

Despite all its good intentions, the educational agenda of reform has not delivered much in terms of mathematics performance of learners for the majority of poor children in schools where they are taught mathematics in their mother tongue in the first four years. With the exception of English and Afrikaans home language children, all the learners will switch to English (or continue to be taught in English), an additional language for them, as the language of the classroom by Grade 4 and will be tested in this language (except Afrikaans children, who will continue to be tested in their home language). In the foundation phase, the ANA tests are administered in children's classroom language. From the recent report by the National Education Evaluation and Development Unit (NEEDU, South African Department of Basic Education, 2013) it is evident that an unknown, but probably significant, number of children enter classrooms in which they do not know the (African) language of the education in their schools. It is no longer possible to argue away the conundrum of language of learning and teaching (LoLT) by citing ideological belief or bilingual education research in countries like the US and Canada, with little psycholinguistic reference (Henning, 2012). The conditions on the ground are very different in South Africa. 
Coupled with the issue of the language of education and of national testing in the foundation phase is the issue of the value or usability of the tests themselves, especially in the foundation phase. While sympathetic to the need to see how schools are implementing the curriculum and how teachers are using workbooks and other materials, and assuming that test performance of learners will give some indication of teacher competence, I am concerned that the results do not yield much new information on the state of the mathematics and the literacy of young children. I suppose that substantial amounts from the national education budget is spent on this massive undertaking; I wonder if it could not be better spent on a huge drive for teacher development and extensive testing of a small sample of learners to diagnose their ability comprehensively. For example, does it take such a large-scale effort to conclude that young children struggle with verbally formulated number problems, especially if the translations into different languages result in some ambiguity with regard to constructs of time, space and number? The literature on variance of language describing mathematical concepts is evidence to this (Bowerman \& Choi, 2003; Spelke, 2003; Levinson, 2003; Bowerman \& Levinson, 2001).

In addition to the issues of translations and reformulations of tests in different languages and the challenges this brings to the testing enterprise, the very notion of a 'national' diagnostic test needs to be unpacked. Like the grade 12 exam, an ANA test captures only some knowledge and competence for which a learner has been prepared according to the curriculum. The main assumption of such tests is that individual children across the country will be able to engage 'equally' with the test because of curriculum coverage, with an equal chance of success, because they all learn from the same curriculum and have the same workbooks and are governed by the same national education department. Of course, in a socially stratified country with a very diverse learner population this is not possible. However, the ideal is set in the curriculum.

There is, with this ideal, also the assumption that the test will test mathematical constructs as taught by teachers according to the curriculum and that there is some clear (linear) relationship between these three entities:

1. The curriculum with its embedded maths concepts and the latent psychological constructs that can be tested in an operationalised fashion;

2. The teacher who mediates these concepts; and

3. The learner who engages with the teacher and the material, much of which is presented via language as a system of signification.

Yet, it is surprising that the three curriculum reforms in the last 12 years have been based on an as yet unclear diagnostic image of what the vastly diverse children of the country are capable of at the same age in, for example, grade $\mathrm{R}$ and grade 1 . There has been no standardised test (in any of the 11 official languages) that can diagnose children's competence in mathematics in this age group. In fact, there has not been any standardised new test originating in the country for the last 30 years or more (JET 
Education Services, specialist manager, personal communication, June 2013). To my knowledge there has also been no use of a standardised test in any of the local African languages in which children are assessed diagnostically for their cognitive ability, in general, except the pilot studies initiated by Helen Dunbar-Krige, using a test that was designed decades ago and which has not been adapted since then. According to Dunbar-Krige (personal communication, June 2013) there is also some work in test development and amendment at Rhodes University.

\section{The ANAs as diagnostic measures?}

Unlike the main assertion in the 'diagnostic report' (South African Department of Basic Education, 2013) I would argue that the annual national assessments (ANAs) for foundation phase mathematics competence are not truly diagnostic, but describes learners' performance as a reflection of a school's curriculum implementation and coverage. In the foreword (ibid, 2) to the report, the Minister of Basic Education writes:

The purpose of this Diagnostic Report is to highlight and present to teachers and School Management Teams (SMTs) specific areas of Language and Mathematics knowledge and skills in which learners who participated in ANA 2012 were found to be inadequately equipped. The evidence in this report must be built into normal teaching programmes and also used to inform specific interventions to improve the levels and quality of learner performance in schools.

The 'areas of weakness' in mathematics (grade 3, 6 and 9) presented in Table 4.1 (South African Department of Basic Education, 2013:6) includes almost the whole curriculum. The report, if it diagnoses anything, it is not so much a comment on learner competence as broader systemic problems.

One systemic problem would be the categorising the tests as diagnostic. I do not think that individual children's competence can be aptly diagnosed by a group tests administered orally (in grade 1 and 2) by their teacher, or in a written pencil and paper test (in grade 3), both of which are scored by their teacher. Many contextually confounding factors are simply not taken into consideration. I also think that without an explication of the theoretical underpinnings of such a test, with its numerous constructs (which is a glaring error by today's testing practices), the chances that it could be valid are slim. The list of 'mathematical skills and knowledge' that are 'inadequate' according to the report (South African Department of Basic Education, 2013) is long and it refers to almost all aspects of the curriculum. The list of strengths is nothing less than heart breaking. I would guess that the competence level on a conceptual model of mathematics competence would be in the first or second level on a scale of five. The divide in mathematics education, on this evidence, is astounding. The interventions suggested in the report are, to my mind, no more than pedagogical first aid remedies.

I would argue that the validity of the ANA tests, as diagnostic measures, would be hard to endorse. There is simply too much room for variance in these nationally administered tests, one of which is coherence of the language (and discourse) of the test, the language of the classroom and the language of the home. There is also a 
void with regard to the theories that have informed the design of the tests. I have argued elsewhere (Henning, 2013) that foundation phase teachers practise pedagogy on reductionist notions of radical constructivism in a narrow Piagetian sense, not taking cognisance of research in the cognitive sciences during the last 30 years. I would assume that similar constructivist epistemologies constitute the framework for the tests.

Nevertheless, the fact is that the tests do not state explicitly what the constructs are that children learn and that are tested, and as such they remain descriptive tests that assess some curriculum knowledge. I am not referring to mathematical operations only here, but to the psychological constructs of number, space and time that are made observable in children's mathematical operations. The constructs, if not explicated, can only be assumed or inferred. I argue that the country needs to use locally standardised tests, normed for the learner population, to inform the curriculum and on which future ANA designs can be based. Such tests can be conducted with a sample of learners countrywide so that the curriculum, specifically its suggestions for pacing, but also its range of content, can be adjusted according to findings that can lay a legitimate claim to validity. At the moment the ANA test for mathematics in the foundation phase measures how far the teacher has progressed with the curriculum and how the learners have been able to keep up with her/him. In my view, it is hard to accept the argument that the tests are a measure of 'national competence'.

It is from this position that I relate the narrative of a European test that arrived in South Africa most fortuitously at a time when educational measurement in South Africa may be at a crossroads.

\section{The adoption of the MARKO-D test by a South African research centre}

In the last few years, a group of researchers and their students have entered the arena of standardised testing of mathematical competence, aiming to deliver a test that can be used as a diagnostic test for individual children. Lyn Teixeira (2013:1), who is capturing the development of the South African version of the MARKO-D test in her doctoral study, argues in her research proposal:

This study will investigate the process by which a standardised German test, the MARKO-D, has been adapted and translated for use in South Africa with the aim of standardising the instrument if it proves valid for use in the South African context. The test measures mathematical and arithmetical cognitive development and is designed for use in early childhood (ages 4-8). The test was originally designed to assist teachers and psychologists to diagnose mathematical cognitive competence so that early remediation can take place if necessary. The test is designed for use with the individual child; however, I propose that use of a test such as this on a larger scale will also lead to addressing strengths and challenges in the national curriculum and pedagogical practices. 
It all started with a plan to capture children's learning over time at a new school in Soweto, Johannesburg in 2009 and 2010. The school, with its first cohort of grade R learners, was founded as a teaching school spearheaded by the dean of the education faculty, Prof Sarah Gravett, who was also instrumental in building the capacity of the CEPR research programme by, among others, appointing both Annemarie FritzStratmann (University of Duisburg-Essen) and Max Bergman (University of Basel) as visiting professors. The term, 'teaching school' is used in South Africa for schools that are attached to university teacher education programmes. Coupled with the many objectives for the founding of such a school was the plan to capture the first cohort of leaners' growth over the first four years of their school life. In a panel research project, initiated by Max Bergman and his team from the sociology department at the University of Basel and a team in the CEPR at the University of Johannesburg, we designed a research programme in which children's language, literacy, mathematics and science knowledge and overall academic competence would be growth-modelled. There were 80 learners in two classes, one of which housed Sesotho-speaking children and the other isizulu speakers. Custom-designed instruments were implemented to test the children as soon as was possible in their grade $R$ year. Some of this early piloting work was published and served as field of study for eight master's students and one doctoral candidate.

While searching the internet for examples of how to go about translations of existing tests that were available commercially from the English-speaking world, Anita Keller, who worked in the Basel team, came across references to the work of researchers in Germany. Their contact was Prof Annemarie Fritz-Stratmann at the University of Duisburg-Essen. The first meeting of the two groups in Europe was the catalyst for the import of the MARKO-D test from Germany to South Africa. What was a search for help with translation had led to the use of the German test. Various pilot studies ensued and the promise of a first standardised test for mathematical competence of children in the foundation phase, making provision for norms that would include learners who learn in their home language and learners who learn in an additional language, is becoming a possibility.

\section{The Basel, Duisburg-Essen and Johannesburg connection}

When the chance meeting of a sociologist and political scientist with a keen interest in educational and social development (Bergman), and an educational psychologist (Fritz-Stratmann) took place in Cologne a few years ago, they probably had no idea what effect the initial collaboration would have on the research programme that would follow on this meeting.

Soon after their encounter, the first translation of the test from German to English was used in a pilot with grade 1 learners, after this version had been re-translated to isizulu and Sesotho. The translations were piloted with the two classes of grade 1 children, who were the participants in the panel research. The idea was to use the instrument, with additional more difficult items, as they progressed through to grade 
4. However, the translations proved to be ineffective in many ways. We found that the African language versions were too formal, having been done by academics who teach the languages at university and who did not really know the discourse of local foundation phase classrooms. It was also clear by then that the English translations had remained too 'German' in style and were missing the colloquialisms of classrooms and street life in South Africa.

At the same time the first pilot results were of interest because the South African cohort's performance compared well with the German ones, where the test had been administered to more than 3,000 children (Fritz, Ehlert \& Balzer, this issue). With the help of the local test administrators, students at the university and practising teachers, the translations were subjected to four rounds of adaptation and re-translation, taking into account the dialecticalisation of the African languages. A leading role was played by the resident school researchers, Dikeledi Sekhukhune and Daphney Mawila, who were assisted for a while by Nick Welch, who knows the isizulu dialects of urban South Africa. Jerry Maseko and Senoelo Nkhase also assisted with the translation and reformulation of the tests.

In the second year of the testing, a new master's student, Hanrie de Villiers, had joined the research group, by then including two doctoral students as well. She translated the test into Afrikaans and administered it at the school where she teaches and one other school. She also put us in touch with an artist who created the meerkat characters, Jobo and Lona, in the most recent illustrated version of the test. The original German 'cover story' had squirrels as characters.

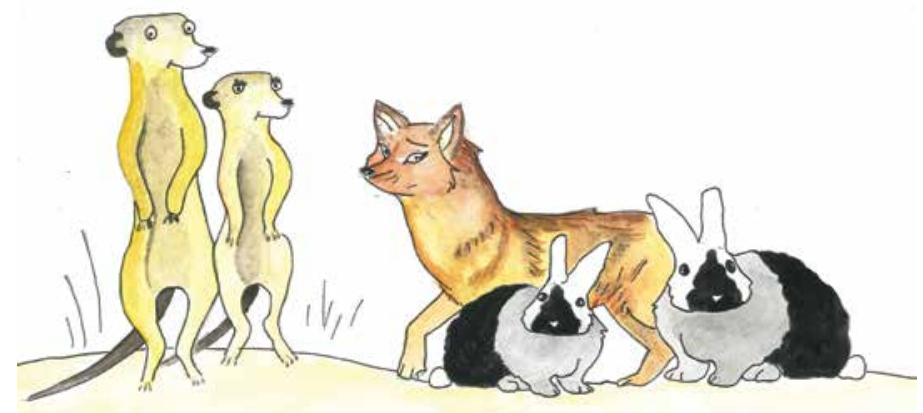

Figure 1: Animal characters in the MARKO-D test.

After this, the test was ready to be administered to a larger number of grade $\mathrm{R}$ and grade 1 learners. We had moved beyond the boundaries of just one school and in February and May 2013, over 800 children from 15 schools in Johannesburg were tested in four languages. The most recent results will be made known at a public 
seminar in August 2013, when we will be in a better position to know what else will need to be done to ensure that the test will be eligible for standardisation. The details of the norming are still under discussion, but indications are that there will be dual norming, which will entail dividing the population into two parts: learners who are educated, for the most part of their school career, in the language of their home and those who are educated through medium of English, but who do not use it as the main home language. The latter would then include all the African languages, immigrant languages and all the dialects of the various languages.

\section{An emergent research group and a community of practice}

The organic formation of the initial research group already had the makings of a budding community of research practice. It was unusual for a research project in primary school education to be led by a scholar known as research methodologist, editor, political scientists, and sociologist. Yet, I would argue, that Max Bergman sparked energy and interest because he looked at education from a macro-social perspective. He laid a firm foundation and with the help of members of the institute in Basel where he was director at the time, notably Anita Keller, Robin Samuel and later Zinette Bergman, he steered the panel research competently and with good vision. It would be safe to say that he laid the foundation and initiated methodological discussion.

In the meantime, the local interest grew and the collaboration with the DuisburgEssen team gained momentum. Annemarie Fritz (Fritz-Stratmann), Petra Langhorst and Antje Ehlert came to Johannesburg in 2012 and we forged a plan to strengthen the pilot work, to include more children and to aim for eventual standardisation. In a joint research plan, with tests administered in both South Africa and Germany during the same window of reliability, a firm collaborative research project was cemented. In April 2012, the decision was made to publish a special issue of the SAJCE, with the theme of early mathematics development and assessment. The executive board of the journal agreed to invite Annemarie Fritz and Graham Dampier, a local member of the research team in the CEPR since mid-2011, to be the guest-editors of the issue. The idea was to prepare, for the South African readership and the new research organisation, the South African Research Association of Early Childhood Education (www.saraece. org.za), a set of articles that would highlight the nature of the German-South African collaborative work, not only for academic interest, but also for possibilities of future collaboration across the two countries.

Annemarie Fritz, apart from her role as guest editor and author, is also cosupervisor of one doctoral and one master's student, while serving on the doctoral committee of two doctoral students in the programme. Upon looking back at the evolvement of the Team MARKO SA, it is evident that it is an organically constituted team that developed not only because of shared academic interest, but also specifically because of the shared ideal of crossing the divide in South African foundation phase mathematics education. I think this is the intersection where the collaboration crossed the boundary into becoming a community, a 'Gemeinschaft'. It has elements of innovation, apprenticeship, social learning, shared interest, and collaboration, none of 
which was designed, and all of which evolved from meeting with people. These are core qualities of what Lave and Wenger have termed communities of practice (Lave \& Wenger, 1991).

The early work of Jean Lave (1988) can be read as a mirror of what happened in the growth of this research group. Although she wrote about mathematics in everyday life, similarities can be drawn between that and 'research in everyday life'. The everyday life of the academy, especially a small education practice research centre at an urban university, is closely linked to what goes on in education at its geographical borders. The centre is in Soweto and is within walking distance of the school that was mentioned earlier. For researchers in the centre, the pilot studies practice at the school was indeed 'cognition in practice' - the title of Lave's early book. It was unthinkable that the centre would venture elsewhere for its research 'cognition' when there was a live laboratory on its doorstep.

In the collaborative work of Lave with Etienne Wenger (Lave \& Wenger, 1991), 'situated learning' and 'legitimate peripheral participation', the wording of the title, neatly captured the content of their book. They explored the forming of practice communities and highlighted how newcomers learned from 'old-timers' and how some members moved on to other work, while the core of the community remained steadfast. Team MARKO SA evolved with some 'old-timers' moving on, leaving a legacy and with many newcomers, especially research students, joining the team. Some of the members are the funding agencies that support this work. Another group of members are the specialist manager, Roelien Herholdt, the junior research officer, Nozipho Motolo, and the intern, Barbara Koekemoer, from JET Education Services, who collaborate on test administration and data capturing and analysis.

The current core team in Johannesburg consists of myself, Graham Dampier, Lara Ragpot, Helen Dunbar-Krige, Daphney Mawila, Jerry Maseko, Senoelo Nkhase, Lyn Teixeira, Hanrie de Villliers, Bronwyn Blake, and 45 students in the BEd programme, who assist with testing, continue to work together in studies of literature, meetings on data analysis and strategies for the furture. New members joining as researchers are Nokwanda Mbusi (PhD) from UJ's Siyabuswa campus, Ingrid Reyneke (MEd, previously Bed Hons member), Adele vd Bergh (MEd, previously BEd Hons member) and Ulana Brits (BEd Hons) member. The members and other participants recently attended a two-day winter school course in the centre on the topic of 'mathematical cognition in childhood'. Apart from regular monthly meetings of different groups in the community, there is also one public lecture and one public seminar per year, both of which attract much interest from the public. A number of articles have appeared in the Education section of the Weekly Mail \& Guardian newspaper as well. The community is also active on twitter @ElbieHenning.

While conducting research and studying the literature, the group also has to work continuously on surviving in the funding drought for research. The National Research Foundation of South Africa (NRF), the ZENEX Foundation, The University of Johannesburg Research Committee with the Faculty of Education, the South African 
department of higher education and training (DHET) and the ApexHi Charitable Trust have, in various ways, contributed to the strengthening of the community of practice and are regarded as our partners.

The Centre publishes Khululeka, an annual ECD supplement to SAJCE. One of the interesting branches of the work is the making of a video series on mathematical cognition, working with Jessica Denyschen's film company and with Megan Godsell as director. The two-hour series will be premiered early in 2014 and will be distributed to all teacher education institutions in the country where foundation phase teachers are prepared for the profession. The title of the series is \#Taximaths: How children make their world mathematical. It is evident from the title and the title of this article that the firm message regarding mathematics learning is that children learn to see their environment with a mathematical lens and that they need (systematic, planned) instruction to be able to do so. The film is part of the DHET national project on strengthening teacher education for the foundation phase.

Another role that this research community has been fulfilling is to integrate some of the research of two different academic departments on the Soweto campus of UJ. The researchers in the programme work in the Department of Childhood Education and the Department of Educational Psychology, which is chaired by Helen Dunbar-Krige. According to her, this joint work in the CEPR has also strengthened the practice of the UJ Institute of Childhood Education, where community engagement and support is one of its four pillars, along with research, teacher education and development and the education of children in the university's two teaching schools.

\section{From serendipity to finding out how children make their world mathematical}

From the chance meeting of minds and ideas has grown a community (of practice) that can readily be described by Wenger's later work (Wenger, 1991; Wenger et al., 2002). With strong suggestions of cultural historical and activity theory (Engeström 1991), Wenger sees a community of practice as a system that is defined by its membership (in an activity system, a la Engeström). In other words, there is no finite character or identity. The members and their shared interest and motivation are the identity. The members are also one another's teachers and mentors and these roles can shift. In Team MARKO SA Daphney Mawila, Helen Dunbar-Krige and I have remained as the only members since the beginning, with students Lyn Teixeira and Bronwyn Blake conducting research for both their masters and doctoral studies in the community. Graham Dampier joined as research assistant and became co-investigator, while Lara Ragpot joined as supervisor of master's students and scriptwriter. Dikeledi Sekhukhune, the first school-based researcher has just submitted her DEd dissertation on her research, an ethnography of grade $\mathrm{R}$ in the first year of the school's existence.

The Johannesburg team works very closely with the German colleagues and the articles in this special issue of SAJCE bear witness to Team MARKO Deutschland's interest in and commitment to the work, as well as and their eagerness to publish in a new South African journal. ${ }^{1}$ In his explication of the membership of a community of practice 
Wenger notes that 'mutual engagement', 'joint enterprise' and 'shared repertoire' are at the core of a community that work, learn and think together (Wenger, 1998:72-73). I cite from his writing:

- $\quad$ Mutual Engagement: Firstly, through participation in the community, members establish norms and build collaborative relationships; this is termed mutual engagement. These relationships are the ties that bind the members of the community together as a social entity.

- Joint Enterprise: Secondly, through their interactions, they create a shared understanding of what binds them together; this is termed the joint enterprise. The joint enterprise is (re)negotiated by its members and is sometimes referred to as the 'domain' of the community.

- Shared Repertoire: Finally, as part of its practice, the community produces a set of communal resources, which is termed their shared repertoire; this is used in the pursuit of their joint enterprise and can include both literal and symbolic meanings.

In Wenger's later work, when he writes mostly in the discourse of organisationaland knowledge management, he does not refine these thoughts further. He does, however, provide a fine definition of 'practice' in his co-authored book (Wenger et al., 2002:27-29):

While the domain provides the general area of interest for the community, the practice is the specific focus around which the community develops shares and maintains its core of knowledge.

It is what is done in a community that defines it along with the people who perform the activities. Here I am again reminded of activity theory in its classical, Vygotskian form: an activity system is identified by people, actions and objectives (both object of action and Gegenstand, or motivation for action), with the use of tools (Kozulin, 1990; Engeström, 1991).

If a research community produces knowledge and publications, but there is little usable knowledge, it is academic in the narrower sense of the word and in terms of the object of its action, it serves only the academic knowledge community with limited Gegenstand for the education community which it is studying. The community of practice of Team MARKO SA and its conjoined work with Team MARKO Deutschland constitutes, I would argue, a research practice with both an academic, scholarly purpose and a usability (or even advocacy) purpose. It invites action to cross the mathematics education divide in the foundation phase.

\section{A community of practice with a usable knowledge agenda}

Ultimately, in the forging of a community of practice with a research agenda like ours, the goal is to produce usable knowledge that may, benefit learners and their teachers. 
In this, the group the agenda has been clear from the outset. Annemarie Fritz and her team have emphasised that they are driven by the will to have a test for children ready as soon as they can so that we can honestly say we are diagnosing the learners' ability. In the words of Graham Dampier (personal communication, July 2013),

we are diagnosing the ability of learners with a test that is based on a theory of mathematical development that has been tested in various studies. The model posits that mathematical competence develops systematically and that various hierarchical levels of development can be used to assess the level of a learner's ability.

Team Marko Deutschland have gone to great lengths to assist us, convincing the German publisher of the test, Hogrefe Verlag, to give the publication rights of the South African test to a university. German authors have also contributed liberally to this special issue of SAJCE.

As current leader of the group it is my sense that the apprenticeship of Team MARKO SA has been a worthwhile learning experience for most participants, both novices and 'old-timers'. Not only did we learn more about mathematical cognition, have started to study the theorists in contemporary cognitive science, are learning new methods for research and measurement in education, have seen the effects of good (and not so good) practice on learners' school life, but we have also learned some of the rules of engagement with schools and their communities in research practice. In this regard, JET Education Services and the assistance of Delia Arends, the project co-ordinator in the CEPR responsible for research administration, and Memoona Mahomed, a community engagement liaison officer in the Faculty of Education have been of great help. Gadija Petker, who was one of the trailblazers in the establishment of the teaching school, also served the programme in different administrative ways in the establishment of the research.

The most elusive object so far has been to get the attention of the department of basic education (DBE) so that they can decide whether they would be interested to use the test and the others planned in a series on a larger scale. Were that to happen, we would foresee that contentious issues, such as foundation phase teacher education and the need for the best possible expert foundation phase teachers to be deployed to this section of schooling, will receive more attention (currently the training of new teachers is addressed by the DHET in a nation-wide programme).

There is also the issue, always present, of mother tongue instruction in mathematics. We would hope that it will be tackled head-on when findings in a small research programme such as ours already indicate that there is no insurance policy, which guarantees that maths learned in two different linguistic codes is best for young learners. As is known to some readers, I have been arguing that there is no such psycholinguistic insurance policy (Henning, 2012; Henning \& Dampier, 2012) and that we may be jeopardising children's future by not following a pragmatic route of one language only for mathematics instruction in schools. 
Other findings that we can already refer to is that some of the more difficult items on the test are better understood by younger learners. We have also found that children do not seem to learn succession that is not indicated in such as straight line running from left to right. This could mean that they do not learn to abstract the notion of ordinality, which, in turn, could limit their understanding of cardinality, of composition and decomposition of number and of fractions. Other findings so far show that teachers in a small sample have indicated clearly that they teach from a notion of their instructional methods as origin of children's understanding and do not give any/much thought to the children's mathematical cognition or their developmental stage at all (Henning, 2013). They see a direct line between the curriculum, their teaching, and the children's performance. Although their discourse is full of learnercenteredness terminology, their practice is curriculum and pedagogy driven. Why these findings in some of our adjacent research projects are seen as usable knowledge is because I assume we agree that teachers and teaching remain the most important factors in the life of the child who has to master mathematics. If teachers have more freedom to work with the national curriculum in a way that suits the children in the many diverse settings in the country, they may stand some chance to remove 'a blind spot in our culture' and to enter, with children, the 'alien territory' of mathematics (Frenkel, 2013, citing Enzensberger).

I conclude with questions: What if we find, in a (future) national sample of results from a diagnostic test such as the MARKO-D, that the curriculum may be in need of streamlining? What if we then suggest that it should provide more opportunity for depth of learning (and with that 'deep' pedagogy)? What if we suggest the curriculum (and its annual testing instruments) should be aligned with post-constructivist theory of learning (Spelke, 2003, 2010; Carey, 2009, 2010; Devlin, 2012) and development, including the small bit we now know about brain functioning in mathematics (Dehaene, 2011)?

A community of research practice needs to ask questions like these. SA Team $M A R K O$ and the collaborators in Europe are working to formulate more questions and to gradually start suggesting some answers. When I composed the title for this article it crossed my mind that children make their world mathematical with the tools we use to mediate it for them. These tools are mostly semiotic and much of this is linguistic. The formulation of the test items in four South African languages showed, through all the different iterations, that languages are not universal (Bowerman \& Choi, 2003; Levinson, 2003; Bowerman \& Levinson, 2001). Without a diverse group of people in a community, individual researchers may well have missed this and many other issues.

\section{Endnote}

1. The SAJCE is at the time of publication not yet accredited by the Department of Higher Education and Training (DHET) in South Africa. This means that South African authors, who receive liberal subsidy from the education department for publications in accredited journals, are reluctant to submit manuscripts until they have assurance that the journal will 
be given the stamp of approval. The application for accreditation went in after the first four issues and the result will only be known in November 2013.

\section{References}

Bowerman, M. \& Choi, S. 2003. Space under Construction: Language-Specific Spatial Categorization in First Language Acquisition. In D. Gentner \& S. Goldin-Meadow (Eds.), Language in Mind. Advances in the Study of Language and Thought, 387-428. Cambridge, MA: MIT Press.

Bowerman, M. \& Levinson, S.C. (Eds.) 2001. Language acquisition and conceptual development. New York: Cambridge University Press.

Carey, S. 2009. The origin of concepts. Oxford: Oxford University Press.

Carey, S. 2010. Beyond fast mapping. Language Learning and Development 6(3):184-205.

Dehaene, S. 2011. The number sense. How the mind creates mathematics. Oxford: Oxford University Press.

Devlin, K. 2010. The mathematical brain. In D.A. Sousa (Ed.), Mind, brain and education. Neuroscience implications for the classroom. Bloomington, IN: Solution Tree Press.

Engeström, Y. 1991. Activity theory and individual and social transformation. Activity Theory $7(8): 6-17$.

Henning, E. 2012. Learning concepts, language, and literacy in hybrid linguistic codes: The multilingual maze of urban grade 1 classrooms in South Africa. Perspectives in Education 30(4):70-79.

Henning, E. \& Dampier, G. 2012. Linguistic liminality in the early years of school: Urban South African children 'betwixt and between' languages of learning. South African Journal of Childhood Education 2(1):100-119.

Kozulin, A. 1990. Vygotsky's psychology: A biography of ideas. Cambridge, MA: Harvard

Levinson S.C. 2003. Language and mind: Let's get the issues straight! In S.D. Blum (Ed.), Making sense of language: Readings in culture and communication, 95-104. Oxford: Oxford University Press.

South Africa. Department of Basic Education. 2013. National Educational Evaluation and Development Unit. National report 2012: The state of literacy learning teaching in the foundation phase. Pretoria: Department of Basic Education.

South Africa. Department of Basic Education. 2013. ANA Report 2012: Diagnostic Report - Retrieved from http://www.education.gov.za/LinkClick.aspx?fileticket... tabid=424\&mid (accessed 7 July 2013).

Spelke, E.S. 2010. Innateness, choice, and language. In J. Bricmont \& J. Franck (Eds.), Chomsky Notebook, 203-210. New York: Columbia University Press. [Originally published in French: Spelke, E.S. (2007). Innéisme, liberté et langage. In J. Bricmont \& J. Franck (Eds.), Cahier n 88: Noam Chomsky, 197-201. Paris: L'Herne.]. 
Spelke, E.S. 2003. What Makes Us Smart? Core Knowledge and Natural Language. In D. Gentner \& S. Goldin-Meadow (Eds.), Language in Mind. Advances in the Study of Language and Thought, 277-312. Cambridge, MA: MIT Press.

Teixiera, L. 2013. Towards the standardisation of an adapted, translated test of development levels of mathematical cognition in the foundation phase of schooling. Proposal for DEd research in the Faculty of Education at the University of Johannesburg. July 2013. 